\title{
A stereotaxic implant technique for the weanling rat*
}

\author{
CARROLL W. HUGHES. JR.广, GEORGE A. LEWIS, JR. \\ and SHELDON H. PRESKORN $\uparrow \dagger$ \\ W'ichita State Lniversity. Wichita, Kansas 67208
}

A modified technique for permanently implanted electrodes in the weanling rat is presented. As a reliable and durable technique, long-term stimulation of the juvenile rat is made possible.

Stereotaxic implantation of electrodes in the adult rat is common (Thompson. Lindsley, \& Eason, 1966). However, implantation in the very young animal has been neglected due to presumed difficulties of growth, soft skulls, and electrode movement. Valenstein, Case, and Valenstein (1969) have provided a stereotaxic atlas of the infant rat hypothalamus and a technique for lesioning the infant rat, 1, 7, and 14 days of age. The weanling rat, in contrast, as Valenstein et al (1969) note, requires only minor correction of conventional atlases for electrode placement. The technique described here for implanting weanling rats has the advantages of ease of use, high stereotaxic reliability, and a low rate of $S$ mortality.

\section{METHOD}

The Ss were 100 male rats (Sprague-Dawley strain, Sprague-Dawley Company, Madison. Wisconsin) shipped at 21 days of age and housed in the laboratory at 22 days of age. They were housed singly and allowed 1 day of adaptation. On Day 23. the animals were placed on food deprivation in preparation for surgery on Day 24. The animals were scheduled to arrive at staggered intervals in groups of 25, both for practical considerations and in order that age treatments could be controlled. Mean body weight was $45 \mathrm{~g}$.

The rats were anesthetized with an intraperitoneal (IP) injection of a mixture of sodium pentobarbital and chloralhydrate (Equi-Thesin, ${ }^{1}$ dosage: $30 \mathrm{mg} / \mathrm{kg}$ ). A tropine injections were unnecessary. Induction time was 5-10 min. Only four animals did not revive from surgery.

The rat was prepared by shaving the head and cleaning the exposed skin with a $70 \%$ alcohol solution. Instead of the normal midline incision, a circular incision was made. The $1 / 2$-in.-diam cap of scalp tissue was then removed and discarded. The scalp healed faster than is usual with a midline incision, and the subsequent electrode cap was not as irritative. After removal of the scalp cap, the remaining connective tissue was teased free by blunt dissection and the entire skull exposed and cleaned with a $70 \%$ alcohol solution. Little pressure was used because of the thinness and softness of the skull bone. The muscles on the temporal portion of the skull are not well developed as they are in the adult rat, and no problem was encountered in pealing them back.

After hemostasis had been achieved. the animal was mounted in the stereotaxic equipment. As noted above. normal implant

*Reprint requests should be sent to George A. Lewis, Jr., Department of Psychology, Wichita State University, Wichita, Kansas 67208 .

tCurrently at University of Missouri, Department of Psychology, Columbia, Missouri 65201.

$++C$ urrently at Kansas University Medical School, Kansas City, Kansas 66103 . techniques for coordinates can be used (Thompson et al, 1966); however, size corrections were required. Pilot work confirmed by histology provided a skull reference point for the selected electrode site. This reference point was $0.5 \mathrm{~mm}$ anterior to the lamboideal suture and $0.5 \mathrm{~mm}$ lateral to the sagital suture. The electrode tip was lowered to $5.6 \mathrm{~mm}$ below the dura. This area is just medial of the brachium of the caudal colliculus. Teflon-coated .008 (MS 303) stainless steel bipolar electrodes were obtained from Plastic Products, Roanoke, Virginia.

Three stainless steel screws (SC 467 LL, American Optical Co.) were placed in the skull. two laterally from the electrode and one anterior. The screw's were placed in holes drilled with a hand tap. Little pressure was required due to the softness of the skull. After the screws were in place, the hand tap was used to make the hole for the electrode, the dura was nicked with a scalpel, and the electrode lowered. Gel foam was packed around the electrode at the skull surface. Upon final cleaning and drying of the skull surface, the cap was prepared. The strongest and most durable cap was made by placing the dry powder (Cranioplastic Powder, Plastic Products, Roanoke, Virginia) directly on the skull around the electrode and screws and then using a $5-\mathrm{cc}$ syringe to drop the liquid (Cranioplastic Liquid) onto the powder instead of making a cement first. This technique prevented air bubbles. The use of an electric blower (Heat-Blo. Milwaukee Lock and Mfg. Co.) hastened the drying process. Caution: Cranioplastic Liquid is an irritant. If used in excess. it may damage the skull and tissue surrounding the cap.

The animal was removed from the stereotaxic, and if necessary. further Cranioplastic cement was added. No suturing was required, and after removing any remaining residue, the preparation was sprayed with an antiseptic (e.g.. Zephiran Spray, Winthrop Laboratories) or sprinkled with Neosporin to prevent infection. Administration of procaine penicillin was unnecessary. To speed recovery, animals were placed under mild heat lamps to prevent chills. When the animal began to move, he was returned to his home cage and allowed 3 days to recuperate.

\section{DISCUSSION}

We performed 25-30 operations in a day with two to three Es and an assembly line process in which each $E$ had a specific task. Each preparation took approximately $10-15 \mathrm{~min}$. Since caps come off with rough handling (20\% loss over 28 days of daily connecting), a reserve of $S$ s receiving the same treatments is suggested. The loosening of some caps resulted from insufficient cleaning of the very thin layers of muscle tissue from under the cap, i.e., the sterncleidomastoid as well as cranial muscles. Over a period of weeks, this tissue grew and lifted the cap off of the skull. Otherwise. the growth of the skull increased the strength of the cap.

Histological examinations were made to determine tissue damage and to verify accurate placement of electrodes. The animals were lesioned at $1.5 \mathrm{~mA}$ for $20 \mathrm{sec}$ using a Lehigh Valley de lesion maker. The brains were perfused with Formalin and fixed in paralodion blocks for sectioning. Sections were thionine-stained and the lesions recorded (see Fig. 1).

The electrode tips were clustered around a point $1.75 \mathrm{~mm}$ lateral to the midline, $1 \mathrm{~mm}$ anterior to the interaural line, and $5.0 \mathrm{~mm}$ below the dura (Konig \& Klippel. 1963). This general area within the reticular formation was within a safe margin for our purposes but indicated a small amount of error. Either the placement error due to individual skull variation (a skull reference point was used) or movement as a result of growth was responsible for this marginal error. Although histological cxamination at time of sacrifice (50-60 days) revealed no obvious tissue damage due to movement, discretion may be 


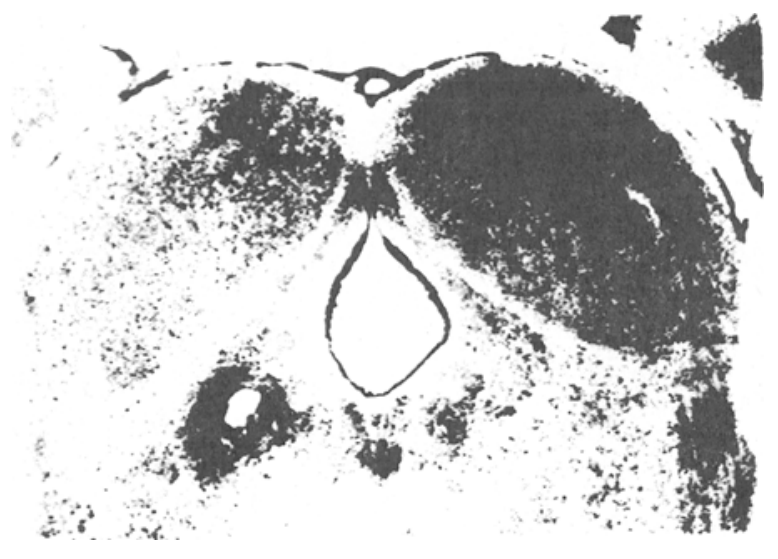

Fig. 1. Section ( 20 microns) showing electrode tip position at 53 days of age.

necessary in selection of very precise electrode sites and in studies using stimulation over a long period of time.

The success of this technique has been shown by Lewis, Preskorn, and Hughes (1971). Weanling rats received electrical stimulation beginning at age 27 days for up to 28 daily 2-h sessions. Tension leads (Receiver Cord 303. Plastic Products) were connected during stimulation, but no problems resulted even though the rats were occasionally quite active.

\section{REFERENCES}

Konig, J. F. R., \& Klippel, R. A. The rat brain, a stereotaxic atlas of the forebrain and lower parts of the brainstem. Baltimore: Williams and Wilkins, 1963.

Lewis, G. A Preskorn, S. H. \& Hughes, C. W. Jr. Biochemical and behavioral consequences of EBS during early development. Paper presented at the meeting of the Southwestern Psychological Association, San Antonio, May 1971.

Thompson, R. F., Lindsley, D. B., \& Eason, R. G. Physiological psychology. In J. B. Sidowski (Ed.), Experimental methods and instrumentation in psychology. New York: McGraw-Hill, 1966.

Valenstein, T., Case, B., \& Valenstein, E. S. Stereotaxic atlas of the infant rat hypothalamus. Developmental Psychobiology, $1969,2,75-80$.

\section{NOTE}

1. Jensen-Salsberry Laboratories, Kansas City, Missouri.

(Received for publication December 7, 1972; revision received February $8,1973$. ) 